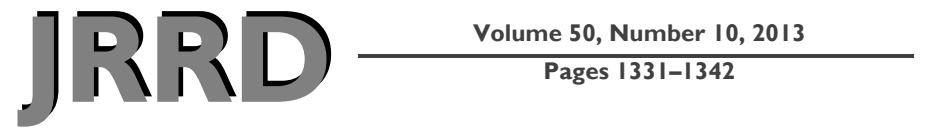

\section{Development and evaluation of prefabricated antipronation foot orthosis}

\author{
Rachel Majumdar, BSc (Hons); ${ }^{1}$ Philip Laxton, MSc; ${ }^{1}$ Anna Thuesen, BSc (Hons); ${ }^{1}$ Barry Richards, BSc (Hons); ${ }^{1}$ \\ Anmin Liu, PhD; ${ }^{1}$ Francisca Arán-Ais, PhD; ${ }^{2}$ Enrique Montiel Parreño, PhD; ${ }^{2}$ Christopher J. Nester, PhD ${ }^{\mathbf{1}^{*}}$ \\ ${ }^{1}$ School of Health Sciences, University of Salford, Salford, Greater Manchester, United Kingdom; ${ }^{2}$ Footwear Research \\ Institute, INESCOP (Technological Institute for Footwear and Related Industries), Elda, Alicante, Spain
}

\begin{abstract}
Our aim was to develop and evaluate a new antipronation foot orthosis that addressed problems perceived by clinicians and users with existing foot orthoses. Clinicians and users were engaged to develop a user specification for the orthosis, and orthotic geometry and materials were developed using clinical reasoning. The orthotic material properties were tested and the ability of the orthosis to reduce foot pronation evaluated on 27 individuals. Clinicians expressed concern that current prefabricated orthoses often did not offer sufficient support to the foot because of a combination of the shape and materials used, and users concurred but also highlighted issues of durability and hygiene. The geometry of the new orthosis was, therefore, adjusted to enable individual foot size orthoses to be produced. A material was selected that was harder and more durable than materials used in many prefabricated orthoses. When the new orthosis was being worn, maximum rearfoot eversion was reduced in both walking (mean reduction -3.8 degrees, $p<0.001$ ) and running (mean reduction -2.5 degrees, $p<0.001$ ). Through a structured process, orthotic design decisions were made that addressed the specific concerns of clinicians and users and the new orthosis was proven to reduce rearfoot pronation.
\end{abstract}

Note: The authors would like to dedicate this article to the memory of their colleague Rachel Majumdar.

Key words: antipronation, biomechanics, eversion, foot, orthotic geometry, orthotic materials, prefabricated orthosis, pronation, rehabilitation, running, walking.

\section{INTRODUCTION}

The clinical objective of most foot orthoses is to reduce the foot pronation that clinicians associate with a range of musculoskeletal problems (e.g., see CastroMéndez et al. and Barton et al. [1-3]). Despite poor reliability of the necessary measurements [4-6], orthoses customized to the shape of the individual user's foot are still considered the gold standard. However, prefabricated orthoses, which are made without tailoring the orthotic geometry to the patient's foot shape, are a fraction of the cost of custom orthoses and appear to have comparable outcomes, or at least better outcomes may not be proportional to the additional cost [7-11]. The work described in this article was initiated because while prefabricated orthoses are in greater demand because of constraints on healthcare resources, anecdotal observations by clinical colleagues indicated shortcomings in the design of prefabricated orthoses compared with custom-made foot orthoses. These shortcomings included inappropriate arch height and low durability of materials. In addition,

\footnotetext{
Abbreviations: $\mathrm{CAD}=$ computer-aided design, $\mathrm{CI}=$ confidence interval, EVA = ethylene vinyl acetate.

*Address all correspondence to Professor Christopher J. Nester, PhD; School of Health Sciences, Brian Blatchford Building, University of Salford, Salford, M6 6PU, United Kingdom; 0161-295-2275; fax: 0161-295-2668.

Email: c.j..nester@salford.ac.uk

http://dx.doi.org/10.1682/JRRD.2013.02.0038
} 
the process by which the shape of a prefabricated orthosis had been determined, a critical feature of custom-made orthoses, and the rationale for the choice of materials were generally unknown. Finally, there was little evidence of the effect of many prefabricated orthoses on foot pronation.

This article describes the development and evaluation of a new prefabricated foot orthosis undertaken as part of a U.K. Government scheme (Knowledge Transfer Partnerships) to transfer knowledge into the healthcare industry. The aim of this article is to (1) report the development of a prefabricated foot orthosis that sought to address shortcomings of existing prefabricated orthotic devices and (2) characterize the material properties of the new orthosis and the effect on foot pronation.

\section{METHODS AND RESULTS}

The project comprised three stages: (1) development of the orthosis specification, (2) development of the orthotic geometry and material, and (3) evaluation of the orthotic materials and the effect on foot pronation.

\section{Stage 1: Development of Foot Orthosis Specification}

To develop a specification for the new orthosis, we appraised a wide range of existing prefabricated orthoses through semistructured interviews with local clinicians who regularly prescribed foot orthoses in public and private health sectors, specialist outdoor and running retailers, and orthosis users (accessed via retail stores and university clinics). The benefits, adverse effects, and good and bad features of different foot orthoses were discussed. Information was captured through written notation and thematic analysis. Seven issues were identified (Table 1). Professionals tended to focus on issues related to biomechanical function and orthotic features that were valued in custom-made orthoses but absent in prefabricated orthoses, such as orthotic geometry (e.g., arch height, heel cup), and the mechanical support offered by the orthotic material. Retailers and users commented on issues related to symptom relief, durability, and value, but also biomechanical function (support for the foot arch).

Table 1.

Issues with existing prefabricated foot orthoses.

\begin{tabular}{ll}
\hline \multicolumn{1}{c}{ Issue } & \multicolumn{1}{c}{ Explanation } \\
$\begin{array}{l}\text { 1. Arch profile of many prefabricated orthoses is too } \\
\text { low. }\end{array}$ & $\begin{array}{l}\text { This prevents appropriate control of rearfoot motion and does not sup- } \\
\text { port joints of medial arch. }\end{array}$
\end{tabular}

2. Little or no heel cup.

3. Materials used in medial arch area are too soft.

4. Over time, prefabricated insoles lose their shape.

5. Top covers or other components can become loose or tear.

6. Top covers can harbor bacteria and dirt.

7. Prefabricated orthotics are often made in limited sizes ranges (i.e., small, medium, large, extralarge), and thus, a single orthotic geometry is intended to provide suitable contact under foot across 1.5-2 shoe sizes.
This can allow some feet to slide laterally off orthosis, potential lack of control of heel motion.

Materials provide insufficient resistance to downward motion of medial arch and eversion motion of heel.

Ability of orthosis to influence foot pronation is short lived, perceived value is low even if initial effect is good.

Layers of orthotic material separating can cause skin irritation, interfere with fit of orthosis in shoe, and make it uncomfortable.

Harboring bacteria and dirt by wicking sweat can encourage foul odor to develop and adversely affect foot hygiene.

Attempting to fit an orthosis across multiple foot sizes can result in poor fit to foot and footwear and require orthosis to be manually trimmed. Use of compliant materials for orthosis is a typical solution to potential poor fit and reduces risk of associated skin irritation. However, this material then offers too little support of rearfoot and medial arch to influence foot pronation. 
Based on the outcomes of the interviews, the aim of the subsequent development stages was to develop a prefabricated foot orthosis that-

1. Was made to specific foot sizes.

2. Had a medial arch profile tailored for each foot size.

3. Comprised a material that offered a high degree of support for the medial foot arch.

4. Was likely to retain its functional properties (geometry and material properties) for extended periods.

5. Reduced the risk of harboring sweat and dirt and, thus, odor.

Making an orthosis for each foot size, and adjusting medial arch height accordingly, was thought to allow a better match to foot shape than the current use of small, medium, and large sizes, which each cover 1.5 to 2 shoe sizes. This might also allow for use of a more rigid material because a narrower range of foot shapes would be using each size of orthosis. Subsequent work (stage 2) sought to identify a model foot upon which to determine the orthotic geometry and to identify a material that was suitable for prefabrication manufacturing processes. The material was also to be comparable to materials widely used for custom orthoses in terms of support for the foot and ideally equally or more durable than materials used for custom orthoses. We decided not to use a top cover in order to reduce risk of harboring sweat. This also reduced the risk of orthotic materials becoming loose. To further improve hygiene of the orthosis, we sought to identify a material that could withstand repeated exposure to water and, thus, enable the orthosis to be easily cleaned.

\section{Stage 2: Development of Orthotic Geometry and Material}

\section{Orthotic Geometry}

To identify a model foot shape for the new foot orthosis, we reviewed 80 existing pairs of foot casts taken by one podiatrist (with $>30$ yr orthotic experience). All casts were from patients prescribed custom antipronation foot orthoses and had been taken with the patient prone, allowing the foot to hang in a relaxed posture. The only cast modification was addition of plaster to the forefoot to align the heel perpendicular to the supporting surface and ensure a flat surface across the five metatarsals and minimal graduating of the adjusted forefoot area to the distal aspect of the midfoot. These cast modifications were all made by the same podiatrist.
The casts were qualitatively ranked by the podiatrist who had taken the casts, and the review process was independently monitored by the principal researcher to ensure consistent reasoning. The aim in this ranking process was to select a single cast toward the median of the 80. Casts with evidence of subluxation or gross pes cavus or pes planus were excluded first because these feet were unlikely to be clinically managed using a prefabricated orthosis. Key features (all assessed through visual/manual inspection) used to rank the remaining casts were ratio of heel and forefoot width, ratio of foot length to heel-to-ball length, abduction/adduction of the forefoot relative to the rearfoot, plantar flexion/dorsiflexion position of the metatarsals compared with heel, and height and length of medial arch as a proportion of foot length. Casts at the extremes of one or more of these features were excluded to gradually reduce the number of casts. This process identified 12 pairs of casts.

Custom-made foot orthoses were manufactured by hand by one podiatrist for each of these 12 pairs of casts using high-density ethylene vinyl acetate (EVA). To explore real-world user acceptance, six symptom-free users trialed each of the six orthoses in random order for $1 \mathrm{wk}$ (in their own footwear). Each was asked to evaluate comfort and fitting of the orthosis in different footwear, report adverse events, and provide overall perceptions. From this process, one orthosis was identified as having the most consistently positive reports from users, and the corresponding foot cast became the model for the new orthosis. A physical model of the new orthosis was then made by heat molding EVA material to the selected cast. Key features of the model orthotic were full length of the foot, creation of a flat underside to facilitate adhesion of orthotic additions, thickness of $3 \mathrm{~mm}$ across the forefoot and $1 \mathrm{~mm}$ in the center of the heel cup to avoid shoe fitting problems, deep sides to the heel cup, extended lateral flange tapered to the fifth metatarsal head, and a chamfer under the medial arch to follow the typical geometry of a shoe upper. We determined the curved shape of the toe box edge (i.e., distal to the toes) by fitting the orthosis in multiple running, outdoor, and leisure footwear styles and ensuring that the anterior edge was not too long or broad in any style.

A three-dimensional computer-aided design (CAD) model of the orthosis geometry was then created by laser scanning the physical model (Figure 1). To adjust the geometry for specific foot sizes, we reviewed the incremental differences in shoe size for various running, outdoor, and 


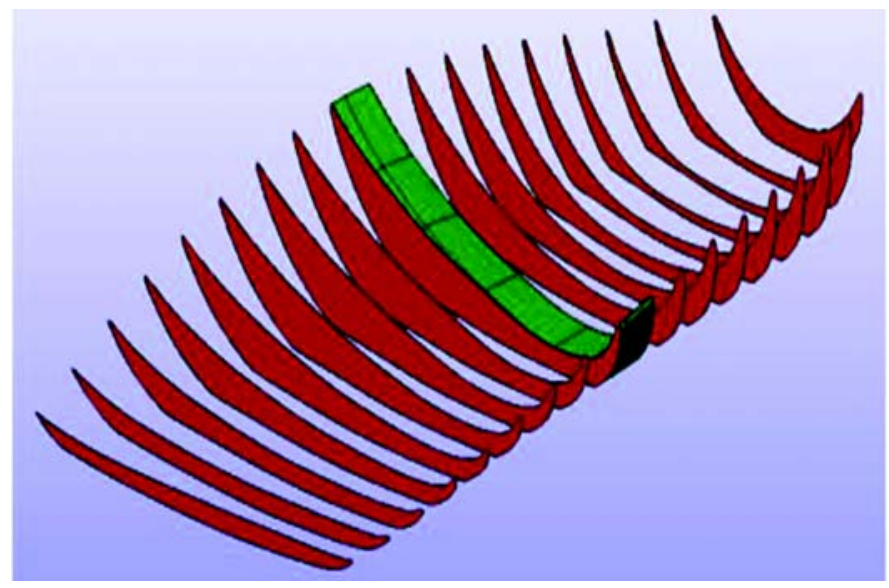

Figure 1.

Frontal plane cross-section geometry of rear and midfoot parts of orthotic (left foot).

leisure footwear. These dimensions were applied to the orthosis length and width, and scaled changes to the rest of the orthosis model were applied. However, the thickness of material under the forefoot and heel was standardized across all sizes to avoid shoe fitting problems. The CAD models were then used to create injection molding cavities for production purposes.

\section{Orthotic Material}

The orthotic material had to satisfy various criteria defined in part 1 of the project. It needed to be stiff in compression so as to control foot motion. However, because the orthosis would be the full length of the foot, the material needed to have low bending stiffness so as to not interfere with toe flexion. In addition, it needed to maintain its properties over the repetitive loading cycles expected during walking and running and withstand immersion in water during washing.

A thermoplastic elastomer was prototyped in various hardness formulations, and the compression stiffness of each was subjectively compared with EVA materials used for custom-made orthoses. Prioritizing the criteria for high-compression stiffness to resist foot pronation [12], subjective inspection identified one material as being comparable to a high-density EVA when produced in a depth equivalent to the medial arch height of the new orthosis $(\sim 1 \mathrm{~cm})$. At the same time, at a depth of $3 \mathrm{~mm}$ (the depth of the forefoot area of the orthosis), it displayed a bending stiffness that was subjectively judged to be less than most retail footwear and, thus, unlikely to adversely interfere with toe flexion. This material was then tested for its behavior in the injection molding manufacturing process, where it is heated to a melted state and injected under high temperature and pressure into aluminum cavities that match the orthotic geometry. The consistency of the material flow into the cavity, the surface aesthetics, and its ability to maintain the complex orthotic geometry during cooling were checked through production of 10 test orthoses.

\section{Stage 3: Evaluation of Orthotic Materials and Effect on Foot Pronation}

The aims of stage 3 were to (1) characterize the material properties of the orthosis in the context of the desired performance criteria (from part 1) and (2) quantify the effect of the foot orthosis on foot pronation.

\section{Material Characterization}

The material was tested to characterize mechanical properties and water and sweat permeability. To produce test pieces of the chosen material suitable for the testing protocols/equipment, we made 150 (length) $\times 30$ (width) $\times 5 \mathrm{~mm}$ (depth) plaques of the orthotic material through injection molding according to the experimental conditions provided by the material supplier. Testing methods are detailed in Table 2.

Results. The orthotic material had a density of $900 \mathrm{~kg} / \mathrm{m}^{3}$; a Shore A (hardness) value of 85; and 37 percent resilience, meaning it returned 37 percent or absorbed 63 percent of the applied energy in testing. After static deformation to 50 percent of the original thickness (compression set test), 13.5 percent of the deformation remained after $30 \mathrm{~min}$ and 8.5 percent after $24 \mathrm{~h}$. There was greater deformation at $50^{\circ} \mathrm{C}$, with 22 percent and 17.3 percent deformation at $30 \mathrm{~min}$ and $24 \mathrm{~h}$, respectively. Under the dynamic compression fatigue test, hardness and resilience were changed by no more than 1 percent after 25,000 loading cycles at 250$700 \mathrm{kPa}$. Remaining deformation was less than 1 percent at both loads.

The insole material had no water vapor permeability and water absorption. There were no recorded changes in material dimensions postimmersion in artificial perspiration solution. Furthermore, there was no evidence of crack propagation under optical microscope viewing after 150,000 flexion cycles with and without immersion in the artificial sweat solution. 
Table 2.

Material tests.

Material Property

Apparent Density

Hardness

Resilience

Compression Set (Static Method)

Compression Fatigue Test (Dynamic Method)

Water Vapor Permeability

Perspiration Resistance

Flexion Resistance

\section{Method and Experimental Description}

Standard ISO 845:1988.

Ratio of weight to volume expressed in $\mathrm{kg} / \mathrm{m}^{3}$.

Standard UNE-ISO 7619-1: 2011.

Degree of penetration of material by standard tool under specified conditions was measured. Hardness meter Shore A was used. Reading is taken 3 s after application of load. Tests pieces: $12 \mathrm{~mm}$ thickness.

Standard UNE 53604:1990.

Energy absorption capacity (expressed as \% of energy applied that is returned) tested using modified Schob pendulum (model 645; Instruments J. Bot. S.A; Barcelona, Spain). Impact energy of $0.2 \mathrm{~J}$ was used. Test pieces: 12 mm thickness.

Standard UNE-EN ISO 1856:2001/A1:2007.

Ability of material to maintain its elastic properties after single compression to $50 \%$ of its original thickness (conducted at $23^{\circ} \mathrm{C}$ and $50^{\circ} \mathrm{C}$ for $22 \mathrm{~h}$ ). Remaining deformation is measured $30 \mathrm{~min}$ and $24 \mathrm{~h}$ after releasing compression and results are expressed as \% of original thickness. Test pieces: 29 mm diameter, $12 \mathrm{~mm}$ thickness.

Standard UNE 59536: 2007.

Remaining deformation of material after repetitive compressive loads (250 $\mathrm{KPa}, 700 \mathrm{KPa}$ ) at $1 \mathrm{~Hz}$ over 25,000 cycles (Compression Fatigue Test Machine, model 5049, MUVER; Petrer, Spain). Measures were taken $30 \mathrm{~min}$ and $24 \mathrm{~h}$ after end of fatigue process. Test pieces: $29 \mathrm{~mm}$ diameter, $10 \mathrm{~mm}$ thickness.

Standard UNE-EN ISO 14268:2003, method C.

Amount of water vapor that flows through material when it is subjected to vapor-saturated atmosphere in closed setting, using distilled water at $32^{\circ} \mathrm{C}$ for $8 \mathrm{~h}$, expressed in $\mathrm{mg} / \mathrm{cm}^{2} \cdot \mathrm{h}$. Permeabiliter (Type CTC, Renaud Electronique; Pierre-benite, France) was used. Test pieces: $29 \mathrm{~mm}$ diameter, original thickness.

Standard UNE-EN 12801:2001.

Ability of material to resist artificial perspiration solution, measured as variation in size (e.g., shrinkage, expansion) postimmersion. Five successive aging cycles were undertaken. Each cycle comprised (1) perspiration immersion at $35^{\circ} \mathrm{C}$ for $24 \mathrm{~h}$, (2) distilled water washing and drying in oven at $40^{\circ} \mathrm{C}$ for $24 \mathrm{~h}$, and (3) conditioning at $23^{\circ} \mathrm{C}$ and $50 \%$ relative humidity for $24 \mathrm{~h}$.

Standard UNE-EN 59532: 1994.

Propagation of cracks in material after 150,000 flexion cycles $(1 \mathrm{~Hz})$ postimmersion in artificial sweat.

EN = European Norm, ISO = International Organization for Standardization, UNE = Spanish Norm. 
Discussion. The chosen orthotic material had three times the density of commonly used cellular EVA materials $\left(85-300 \mathrm{~kg} / \mathrm{m}^{3}\right)$ but similar resilience $(30 \%-55 \%)$ [13-14]. Similar resilience indicates similar energy absorption capacity despite increased density. The material hardness was comparable to high-density EVA materials that are used in some custom-made orthoses. These are typically considered to be toward the upper range of what is tolerable under the foot and are considerably harder than the EVA materials used in many prefabricated orthoses.

At standard testing conditions $\left(23^{\circ} \mathrm{C}\right)$, the orthotic material demonstrated residual deformation $(<13.5 \%)$ after a single compression to 50 percent of its thickness, which was better than the most common EVA (11\%$34 \%)$ and polyethylene (13\%-26\%) materials used for orthoses [13,15]. This indicates an improved ability to maintain its original shape under static loads and, therefore, better durability. Other cellular materials have even better performance, such as polyurethane $(<1.3 \%)$ and latex $(6 \%)[13,15]$, but these have much lower hardness and, thus, offer far less support of foot structures. Greater deformation under the $50^{\circ} \mathrm{C}$ condition is explained by the higher fluency of the polymer chains at higher temperatures.

Results for tests that better replicate real-world use of the material, application of $250-700 \mathrm{kPa}$ at $1 \mathrm{~Hz}$, demonstrated very high durability of the material, losing just 1 percent of its original thickness after 25,000 loading cycles. Hardness and resilience were likewise unchanged after this loading. The fatigue resistance of a thermoplastic elastomer material is due to its elastomeric phase, which determines rubberlike properties such as elasticity, flexibility, and low compression set. In the case of EVA foam, according to Verdejo and Mills [16], foam fatigue is due to the compression and recovery processes of the cellular structure, which produce a decline in the initial compressive collapse stress (elastic limit) and, consequently, softening of the material over time. Furthermore, the absence of any evidence of crack propagation after 150,000 flexion cycles of the material treated with an artificial perspiration solution is further evidence of the high durability.

The orthotic material demonstrated no water absorption and water vapor permeability, similar to those cellular materials with closed cells like polyethylene or EVA foams. This means the material has very low wicking properties and will not retain sweat within the material structure, although it will remain on the orthotic surface. Therefore, the moisture has to be absorbed elsewhere, by a sock or the skin, or reside between the sock and orthosis or sock and skin. However, the low water vapor permeability in addition to the high chemical resistance of thermoplastic elastomers means that washing is unlikely to affect material properties and, thus, the orthotic surface can be kept clean.

While the tests performed allow direct comparison to other materials and conform to accepted industry standards, they do not identify the material properties of the orthosis itself because this is always a combination of the material and the orthotic geometry. However, these properties are complex and variable, depending on many factors, including the shoe in which the orthosis is used and the direction of loading (user specific) and for some parts of the orthosis, the orthotic size.

Overall, the material tests suggest the material is comparable to high density EVA material in terms of hardness and resilience, although it has a higher density. Its durability under compressive loads similar to those experienced during in vivo gait was better than typical EVA materials. Low water permeability properties will allow regular washing without loss of orthotic performance but might require other strategies for moisture management in the shoe.

\section{Effect of Orthosis on Foot Pronation}

Twenty-seven symptom-free subjects aged 18-45 were recruited from the staff and student population of the university. All had a negative history of systemic musculoskeletal disease (e.g., rheumatoid arthritis, diabetes) and surgery that might affect foot posture and biomechanics. Motion of the heel relative to the leg was recorded while subjects walked and ran with and without the orthosis (Figure 2) in a standardized New Balance neutral running shoe (Type M536SR, New Balance; Flimby, Cumbria, United Kingdom). The midsole was EVA with a blown rubber outer sole. Four markers were attached to a plastic plate on the lateral side of the leg. Heel motion was captured using a triad of markers screwed into a plastic disc attached to the lateral side of the heel and protruding through an aperture in the shoe (Figure 3). The alignment of the markers was kept consistent between shoe-only and shoe-plus-orthosis conditions by keeping the plastic disc in situ throughout and using a locating pin to position the triad consistently. Additional anatomical markers on the femoral condyles, 


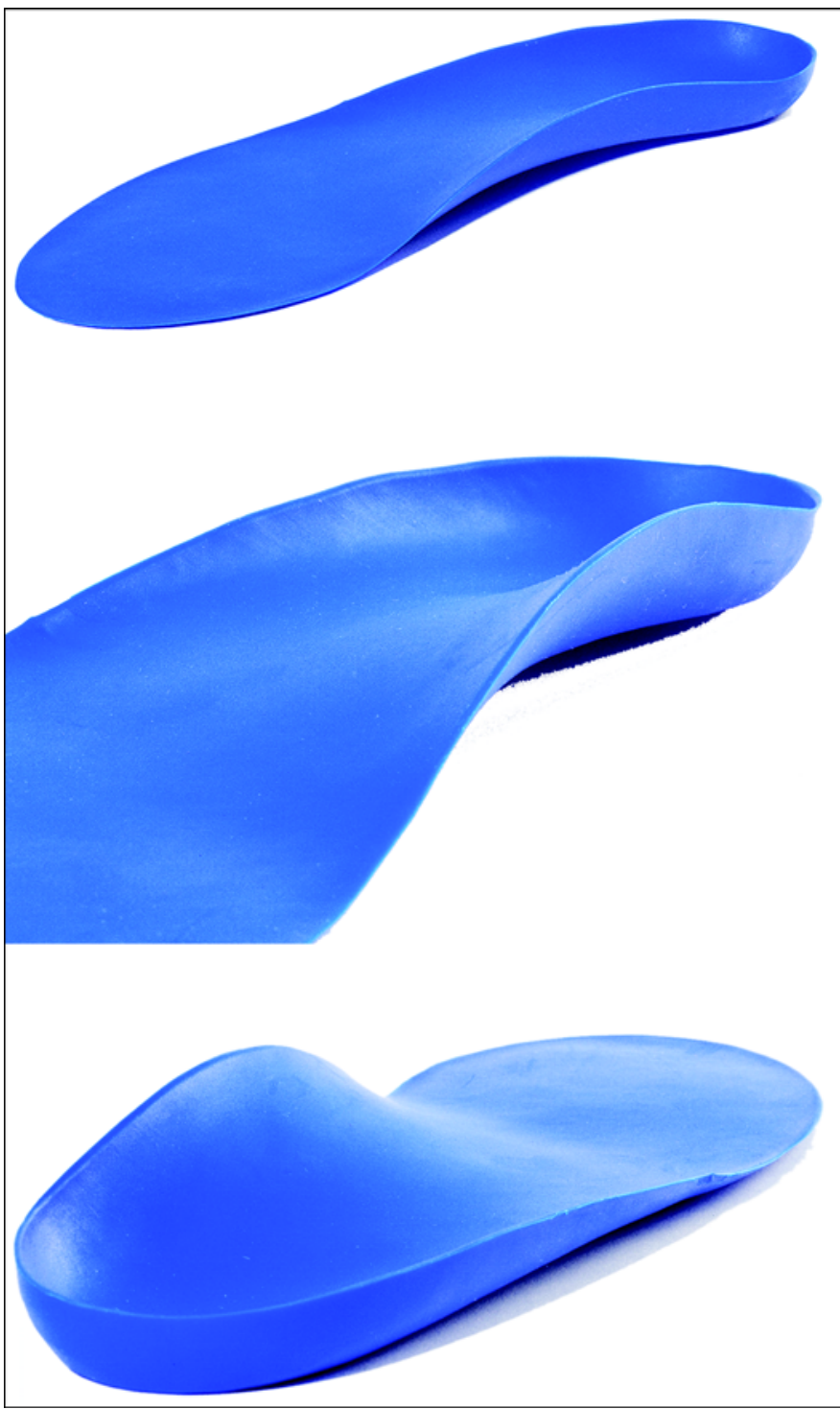

Figure 2.

Orthotic manufactured in chosen thermoplastic elastomer.

malleoli, posterior heel, and second metatarsal head were added during a static trial in the shoe-only condition.

Kinematic data were collected using 10 Qualisys ProReflex cameras $(100 \mathrm{~Hz}$, Qualisys AB; Gothenburg, Sweden). Participants walked/ran over three force plates (500 Hz, Advanced Mechanical Technology, Inc; Watertown, Massachusetts) to detect initial contact and toe off and passed through infrared timing gates $(10 \mathrm{~m}$ apart, within a 20 m-long walkway) to measure speed. Selfselected walking/running speeds were determined through multiple pretrials and only subsequent trials

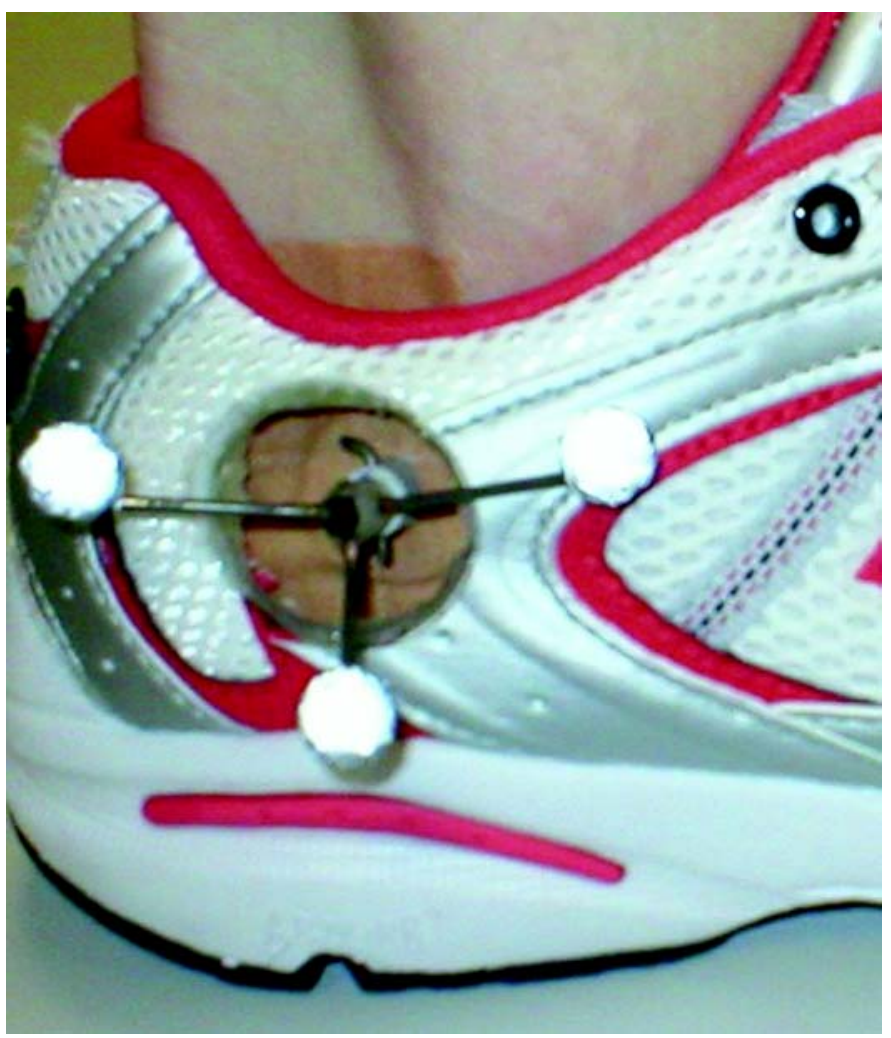

Figure 3.

Three markers mounted on metal triad, attached to lateral heel via aperture in heel counter threaded onto rigid plastic base that was taped to lateral heel.

within 5 percent of the target speed were accepted. Ten gait cycles were collected in each of the four conditions.

All calculations were conducted using Visual3D (CMotion, Inc; Germantown, Maryland). The shank and heel segments were represented by a local coordinative system. The vertical ( $z$ ) axis of the local shank frame was defined using the knee and ankle centers (midpoints between femoral condyles and malleoli, respectively). The anterior/posterior shank axis ( $y$ ) was perpendicular to a plane defined by the femoral condyle and malleoli markers. The medial/lateral shank axis $(x)$ was perpendicular to the other two shank axes. The heel local frame orientation was set such that in relaxed standing, the $Z$ (vertical) axis was perpendicular to the floor (XY of global system) and the $y$ (anterior/posterior) axis was perpendicular to $x$ but parallel to the markers on heel and second metatarsal in the static trial. The $x$-axis was perpendicular to the other two axes. Joint rotations (heel relative to shank) were calculated using Cardan angles 
(sequence $x, y, z$ ). All data were normalized to $0-100$ percent of stance phase, and $0^{\circ}$ was the joint position in relaxed standing in the shoe-only condition.

A change in the peak eversion of the heel relative to the shank was the primary measure of orthotic effect. The peak eversion angle in shod and orthotic conditions was compared in the walking and running trials using paired $t$-tests $(p<0.05)$ (SPSS version 19.0, IBM Corp; Armonk, New York).

Results. There were no differences between kinematic effects for left and right limbs; therefore, data for the left limb are presented. When the orthosis was being worn, maximum rearfoot eversion was reduced in both walking (mean reduction $-3.8^{\circ}$, 95\% confidence interval [CI $2.7^{\circ}-5.0^{\circ}$ ) and running (mean $-2.5^{\circ}$, 95\% CI $1.3^{\circ}-$ $\left.3.6^{\circ}\right)(p<0.001)$. The mean change in the frontal plane rearfoot position during stance is illustrated in Figure 4. The reduction in the eversion position was greatest between $10-60$ percent of stance for walking and between 20-60 percent for running.

Discussion. The mean reduction in rearfoot eversion produced by the new orthosis was greater than the effect size calculated through meta-analyses of the literature (3.8 ${ }^{\circ}$ vs $2.1^{\circ}$ from Mills et al. [17] and $2.2^{\circ}$ from Cheung et al. [18]). The reductions in peak eversion during running were smaller than walking, we assume because the forces involved are greater, and thus, the effect of the orthosis on kinematics was reduced. In common with other reports, effects were subject specific and varied in terms of whether they occurred only in the initial phase of stance or, in some cases, throughout stance. A critical issue is how much change in peak eversion is required to resolve clinical symptoms associated with foot pronation. This has not been clearly defined by prior research. Our study was motivated by current clinical practice that assumes that some reduction in eversion is desirable. Because the observed effects are greater than some of those previously reported, if motion change is important, then the new orthosis might be more effective. However, whether the greater reduction in eversion we report is necessary or still insufficient is not yet known.

The reported changes in eversion were achieved despite the fact that the geometry of the orthosis was based on a foot that was not in the subtalar neutral position advocated for custom orthoses [19]. The poor reliability of subtalar neutral position is well documented [4], as is the fact that it is not a position the foot assumes during gait [20]. Indeed, recent work suggests that the (a)

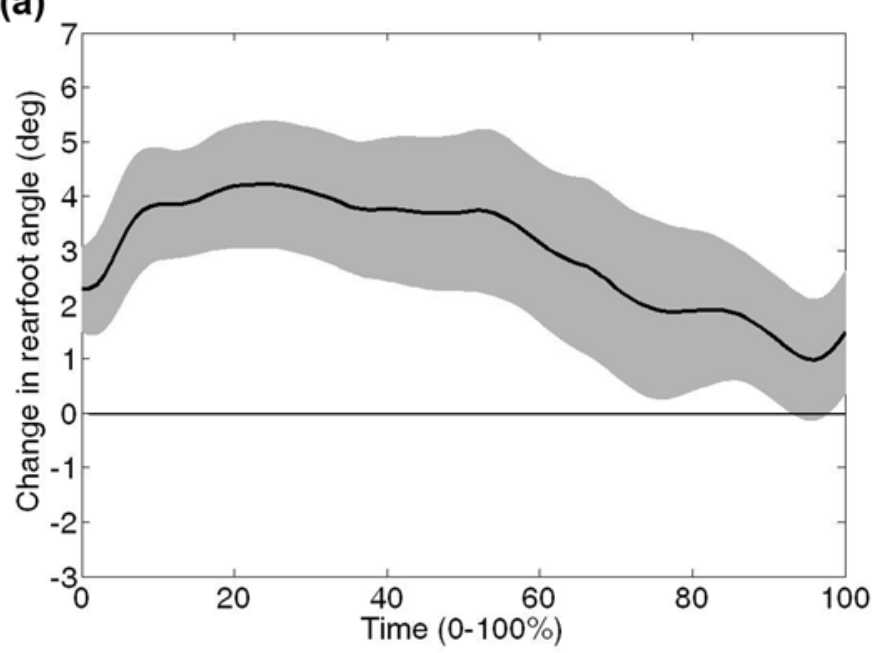

(b)

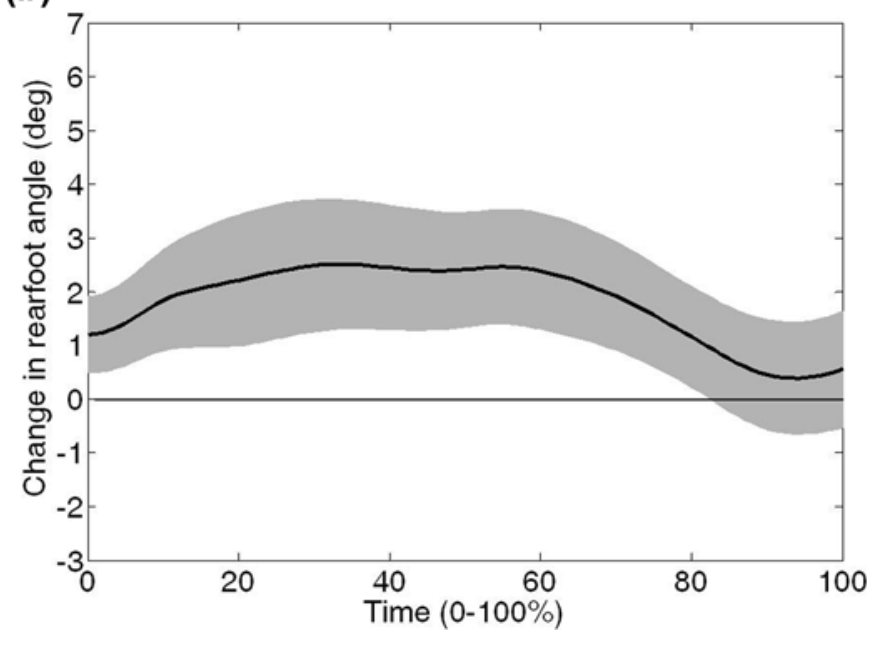

Figure 4.

Mean change in frontal plane rearfoot angle ( $\pm 95 \%$ confidence interval) when wearing orthosis during (a) walking and (b) running. +ve angle indicate more inverted position, or less everted position, when wearing orthosis.

static position of the rearfoot may not strongly affect medial arch shape [6]. While we did not measure plantar loading, the reported changes in eversion must reflect changes in the forces applied to the rearfoot because changes in force are required to produce changes in movement. Changes in external forces applied to the foot should lead to corresponding changes in the opposing internal forces experienced by tissues that might be injured or painful. We assume this is more important than whether the orthotic design relates to or places the foot into the subtalar neutral position. 
One limitation of this evaluation is that we used symptom-free subjects and did not assess the foot type of those studied. However, while specific features of foot motion, such as heel eversion, are associated with some clinical presentations (e.g., patella-femoral pain [2-3], Achilles injury [21], plantar callus formation [22]), differences between groups are often small and unsystematic. In other cases, rearfoot kinematics are less implicated than is often assumed (e.g., plantar fasciitis [23]). Thus, foot kinematics of those with symptoms are not unique compared with those without symptoms. Furthermore, via their meta-analysis, Mills et al. reported only a $0.17^{\circ}$ difference in the reduction in eversion due to orthoses in injured participants compared with noninjured participants [17]. Rodrigues et al. have recently shown that orthotic response was not different between those with and without anterior knee pain [24]. Finally, the frontal plane rearfoot kinematics of our participants are a good match to those with symptoms in terms of both temporal characteristics of rearfoot motion and values of peak eversion [2-3,21-22,24]. Nevertheless, it is the case that some feet might exhibit a static or dynamic shape and movement profile that means there is little potential for a prefabricated orthosis to reduce rearfoot eversion as intended. For example, if the foot medial arch is very high and unlikely to contact the arch geometry of an orthosis, the orthosis is unlikely to have any effect on foot motion. Our sample might include individuals with such feet, although the implication is that the results therefore underestimate the reduction in rearfoot eversion that might be achieved in more suitable feet (i.e., "pronators”).

\section{DISCUSSION}

The objective of this project was to design a prefabricated foot orthosis that reduced foot pronation, and this was achieved. Prefabricated orthoses typically span 1.52 foot sizes and, therefore, might easily produce an ineffective and/or uncomfortable interface between the orthosis and the plantar surface. Our assumption was that the materials used in many prefabricated orthoses were chosen because the materials will quickly deform if the match between foot and orthotic geometries is poor. This avoids the orthoses becoming uncomfortable but compromises their ability to affect external loading of the foot and foot motion. By adjusting the orthotic geometry for each foot size, we were able to implement a harder material and avoid this difficulty.

Developing a washable orthosis that did not wick sweat was our solution to hygiene issues raised by users. We achieved very low water penetration, which might imply limited harboring of bacteria and that repeated washing will not affect orthotic performance. These both seem like positive attributes from a hygiene perspective. However, this poses a new problem of moisture management. Any device intended to retain foot sweat should be washable because long-term retention of sweat might promote bacteria growth, risk of infection, and odor. Socks rather than insoles or orthoses would, therefore, seem a more suitable method to manage foot moisture.

Previous evaluations of foot orthoses typically offer only limited information on material properties and orthotic geometry. It is, thus, difficult to accurately define in mechanical terms the orthoses tested. Often the mode of manufacture (e.g., customized or prefabricated) is reported, but this is meaningless in terms of dynamic biomechanical behavior of the device because neither the actual geometry nor the material properties are known. To our knowledge, this is the first report detailing the development process for the foot orthotic geometry and simultaneous characterization of material properties.

There are limitations to the work presented here. Firstly, the effect of a foot orthosis is highly specific to the geometry of the upper, lower, and side surfaces (the load bearing surfaces); the dynamic behavior of the materials; the footwear worn (because this influences the forces applied to the orthosis and the dorsal surface of the foot); and the gait of the user (and users were symptom free). Thus, the effects described here are limited to the device tested and would only be transferable to foot orthoses of a very similar geometry and material composition [17]. Secondly, we did not compare the new orthosis directly to other orthoses. However, published metaanalyses on the effect of orthoses on rearfoot eversion arguably provide a more valid comparator for the new orthosis, because they include a far wider range of orthotic designs than could be realistically tested in an experiment (19 orthoses in Mills et al. [17], 13 in Cheung et al. [18]). Thirdly, the selection of foot casts and, thus, orthotic geometry was based on subjective clinical judgment. We would argue this subjective selection was no worse that the well-reported variation in clinical assessment of the foot and ankle [4]. Risk of inappropriate selection of a model cast was reduced by enabling user 
feedback to guide the selection of the final orthotic shape. Finally, we did not evaluate plantar pressure changes when using the orthosis, which might help explain the kinematic response. This was not the focus of the evaluation at this stage, but subsequent research is investigating how changes in orthotic geometry affect plantar soft tissue loading and plantar pressure distribution and whether these effects explain the scale of and interuser variability in kinematic response.

\section{CONCLUSIONS}

We aimed to develop and evaluate an antipronation foot orthosis that addressed perceived compromises between customized and prefabricated foot orthoses. Through a subjective but structured process, orthotic geometry was derived and a suitable material selected. The orthosis was made in specific foot sizes and using harder and more durable materials than in most prefabricated orthoses. The orthotic reduced rearfoot eversion more than recent meta-analyses suggest for existing orthoses. The project was intended to transfer knowledge from academia to industry, and the orthosis developed was subsequently commercialized, with in excess of 40,000 pairs now in use in the United Kingdom and Ireland.

\section{ACKNOWLEDGMENTS}

\author{
Author Contributions: \\ Study concept and design: P. Laxton, C. J. Nester. \\ Support of all laboratory tasks: B. Richards, A. Liu. \\ Completion of orthotic material tests: F. Arán-Ais, E. Montiel Par- \\ reño. \\ Analysis of orthotic material tests: E. Montiel Parreño. \\ Data collection: R. Majumdar, A. Thuesen, B. Richards, A. Liu. \\ Data processing: R. Majumdar, B. Richards, A. Thuesen, A. Liu. \\ Data analysis: R. Majumdar, A. Thuesen. \\ Data interpretation: B. Richards, A. Liu. \\ Statistical analysis: A. Thuesen. \\ Writing of manuscript: R. Majumdar, F. Arán-Ais, C. J. Nester. \\ Acquisition of funding: P. Laxton, C. J. Nester. \\ Study supervision: P. Laxton, C. J. Nester. \\ Financial Disclosures: The study sponsor (a government department) \\ does not have a competing interest and had no role in the project or in \\ manuscript preparation. During the completion of the work, no com- \\ peting interest existed for any author. However, subsequent to comple- \\ tion of the study and prior to writing of the manuscript, Dr. Nester \\ gained a competing interest through equity share in the company that \\ now owns the orthotics tested. Dr. Nester contributed in terms of \\ acquisition of funding, study concept, and design throughout the proj-
}

ect, study supervision (of postgraduate student), and writing of the manuscript. Dr. Nester did not participate directly in data collection, analysis, or interpretation.

Funding/Support: This material was based on work supported by the U.K. Technology Strategy Board Knowledge Transfer Partnership scheme.

Institutional Review: Ethical approval for all stages of the project was obtained from the institutional ethical review board. Participants involved at all stages provided informed consent to participate.

Participant Follow-Up: The authors do not plan to inform participants of the publication of this study because contact information is unavailable.

\section{REFERENCES}

1. Castro-Méndez A, Munuera PV, Albornoz-Cabello M. The short-term effect of custom-made foot orthoses in subjects with excessive foot pronation and lower back pain: A randomized, double-blinded, clinical trial. Prosthet Orthot Int. 2013;37(5):384-90. [PMID:23327838] http://dx.doi.org/10.1177/0309364612471370

2. Barton CJ, Levinger P, Webster KE, Menz HB. Walking kinematics in individuals with patellofemoral pain syndrome: A case-control study. Gait Posture. 2011;33(2): 286-91. [PMID:21194952] http://dx.doi.org/10.1016/j.gaitpost.2010.11.022

3. Barton CJ, Levinger P, Crossley KM, Webster KE, Menz HB. Relationships between the Foot Posture Index and foot kinematics during gait in individuals with and without patellofemoral pain syndrome. J Foot Ankle Res. 2011;4:10. [PMID:21401957] http://dx.doi.org/10.1186/1757-1146-4-10

4. Jarvis HL, Nester CJ, Jones RK, Williams A, Bowden PD. Inter-assessor reliability of practice based biomechanical assessment of the foot and ankle. J Foot Ankle Res. 2012;5:14. [PMID:22716130] http://dx.doi.org/10.1186/1757-1146-5-14

5. Carroll M, Annabell ME, Rome K. Reliability of capturing foot parameters using digital scanning and the neutral suspension casting technique. J Foot Ankle Res. 2011;4(1):9. [PMID:21375757] http://dx.doi.org/10.1186/1757-1146-4-9

6. Lee WC, Lee CK, Leung AK, Hutchins SW. Is it important to position foot in subtalar joint neutral position during non-weight-bearing molding for foot orthoses? J Rehabil Res Dev. 2012;49(3):459-66. [PMID:22773204] http://dx.doi.org/10.1682/JRRD.2011.03.0049

7. Pfeffer G, Bacchetti P, Deland J, Lewis A, Anderson R, Davis W, Alvarez R, Brodsky J, Cooper P, Frey C, Herrick R, Myerson M, Sammarco J, Janecki C, Ross S, Bowman M, Smith R. Comparison of custom and prefabricated orthoses in the initial treatment of proximal plantar fasciitis. 
Foot Ankle Int. 1999;20(4):214-21. [PMID:10229276] http://dx.doi.org/10.1177/107110079902000402

8. Redmond AC, Landorf KB, Keenan AM. Contoured, prefabricated foot orthoses demonstrate comparable mechanical properties to contoured, customised foot orthoses: A plantar pressure study. J Foot Ankle Res. 2009;2:20.

[PMID:19531262]

http://dx.doi.org/10.1186/1757-1146-2-20

9. Landorf KB, Keenan AM, Herbert RD. Effectiveness of foot orthoses to treat plantar fasciitis: A randomized trial. Arch Intern Med. 2006;166(12):1305-10.

[PMID:16801514]

http://dx.doi.org/10.1001/archinte.166.12.1305

10. Paton JS, Stenhouse EA, Bruce G, Zahra D, Jones RB. A comparison of customised and prefabricated insoles to reduce risk factors for neuropathic diabetic foot ulceration: A participant-blinded randomised controlled trial. J Foot Ankle Res. 2012;5(1):31. [PMID:23216959]

http://dx.doi.org/10.1186/1757-1146-5-31

11. Richter RR, Austin TM, Reinking MF. Foot orthoses in lower limb overuse conditions: A systematic review and meta-analysis-critical appraisal and commentary. J Athl Train. 2011;46(1):103-6. [PMID:21214358]

http://dx.doi.org/10.4085/1062-6050-46.1.103

12. Paton J, Jones RB, Stenhouse E, Bruce G. The physical characteristics of materials used in the manufacture of orthoses for patients with diabetes. Foot Ankle Int. 2007; 28(10):1057-63. [PMID:17923055]

http://dx.doi.org/10.3113/FAI.2007.1057

13. Faulí AC, Andrés CL, Rosas NP, Fernández MJ, Parreño EM, Barceló CO. Physical evaluation of insole materials used to treat the diabetic foot. J Am Podiatr Med Assoc. 2008;98(3):229-38. [PMID:18487597]

14. Healy A, Dunning D, Chockalingam N. Materials used for footwear orthoses: A review. Footwear Science. 2010;2(2): 93-110. http://dx.doi.org/10.1080/19424280.2010.486045

15. Mata A, Vega-Baudrit J, Montero M, Pereira R, Sáenz A. Estúdio biomecánico de materiales poliméricos para la fabricación de plantillas ortopédicas. Tecnol Ciencia Ed. 2001;16(2):69-76. Spanish.

16. Verdejo R, Mills NJ. Heel-shoe interactions and the durability of EVA foam running-shoe midsoles. J Biomech. 2004; 37(9):1379-86. [PMID:15275845] http://dx.doi.org/10.1016/j.jbiomech.2003.12.022

17. Mills K, Blanch P, Chapman AR, McPoil TG, Vicenzino B. Foot orthoses and gait: A systematic review and meta-analysis of literature pertaining to potential mechanisms. Br J
Sports Med. 2010;44(14):1035-46. [PMID:19996330] http://dx.doi.org/10.1136/bjsm.2009.066977

18. Cheung RT, Chung RC, Ng GY. Efficacies of different external controls for excessive foot pronation: a meta-analysis. Br J Sports Med. 2011;45(9):743-51. Erratum in: Br J Sports Med. 2012;46(5):373.

19. Root ML, Orien WP, Weed JH, Hughes RJ. Normal and abnormal function of the foot. Los Angeles (CA): Clinical Biomechanics Corp; 1977.

20. Pierrynowski MR, Smith SB. Rear foot inversion/eversion during gait relative to the subtalar joint neutral position. Foot Ankle Int. 1996;17(7):406-12. [PMID:8832248] http://dx.doi.org/10.1177/107110079601700709

21. Munteanu SE, Barton CJ. Lower limb biomechanics during running in individuals with achilles tendinopathy: A systematic review. J Foot Ankle Res. 2011;4:15.

[PMID:21619710]

http://dx.doi.org/10.1186/1757-1146-4-15

22. Findlow AH, Nester CJ, Bowker P. Foot kinematics in patients with two patterns of pathological plantar hyperkeratosis. J Foot Ankle Res. 2011;4:7. [PMID:21306644]

http://dx.doi.org/10.1186/1757-1146-4-7

23. Wearing SC, Smeathers JE, Urry SR, Hennig EM, Hills AP. The pathomechanics of plantar fasciitis. Sports Med. 2006; 36(7):585-611. [PMID:16796396] http://dx.doi.org/10.2165/00007256-200636070-00004

24. Rodrigues P, Chang R, TenBroek T, Hamill J. Medially posted insoles consistently influence foot pronation in runners with and without anterior knee pain. Gait Posture. 2013;37(4):526-31. [PMID:23137595] http://dx.doi.org/10.1016/j.gaitpost.2012.09.027

Submitted for publication February 7, 2013. Accepted in revised form May 15, 2013.

This article and any supplementary material should be cited as follows:

Majumdar R, Laxton P, Thuesen A, Richards B, Liu A, Arán-Ais F, Montiel Parreño E, Nester CJ. Development and evaluation of prefabricated antipronation foot orthosis. J Rehabil Res Dev. 2013;50(10):1332-42. http://dx.doi.org/10.1682/JRRD.2013.02.0038

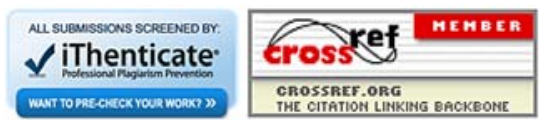


